Journal of Jungian Scholarly Studies

Vol. 2, No. 1, 2006

\title{
Theory Matters: Analytical Psychology and the Human Experience of Despair ${ }^{1}$
}

\author{
Robert L. Moore, Ph.D. \\ Chicago Theological Seminary, C.G. Jung Institute of Chicago, The Institute \\ for the Science of Psychoanalysis
}

Despair is, of course, much on our minds. The people on the Texas coast are awaiting the landfall of Hurricane Rita, even as I speak. We've had much occasion for reflection on the human experience of despair, but I want to talk a little about what despair is and to invite us to think together about how despair manifests in human experience and how it effects our whole approach to theory in psychoanalysis, and then to have a little play together about these issues. Certainly it's hard to be "playful" when we look at theory, but I want to invite us to engage in some play together as we think about these matters.

Let's start by looking at the question of how despair can be defined in a way that is not superficial. I have looked through some 700-plus treatises on despair to see how the word was used. It's quite amazing! People use this word in a wide variety of ways. You can probably compose your own list of synonyms. But if we draw on philosophical and religious thought in some depth, we find that many of these tendencies to equate despair with certain kinds of experiences don't go very deep.

Since we are a gathering of depth psychologists, however, I invite us to go below the surface. First, let me say what despair is not. Despair cannot be limited to the realm of an emotional affect. It's not just about feeling. And, in spite of widespread usage, neither is it a synonym for depression. If you are in despair, you may well experience a great deal of fear, but despair is not fear. Again, while one who is deeply affected by despair may be quite overwhelmed by events and confused about what to do, a person in despair is not necessarily overwhelmed or confused. Neither is despair the same thing as facing death or having to be in armed conflict. Nor is it something that automatically comes when a human being is facing such catastrophic natural disasters as these recent hurricanes. Indeed, even if one has a terminal illness, there is a great deal of evidence that facing the coming of death does not necessarily plunge one into the 'lostness' of despair. 
I want to give you my short attempt at definition and then, in order to lay a foundation for what is to come, we will consider some thoughts offered by Kierkegaard, who was the primal pioneer in the exploration of despair.

Despair can be said to be "a lack of effective connection to power and meaning, which is so severe that it begins to cause a foundational depersonalization and loss of vitality in the psyche." As it proceeds, this lack can become so severe in its undermining effects that it diminishes the capacity of the individual to feel oriented in the cosmos, and it weakens the individual's capacity to act with courage in the service of values and commitments beyond the ego. In the face of both the predictable negativities of life and the eruption of chaos and catastrophe, a person undergoing such a shaking of the foundations over time will experience despair as a rapidly diminishing access to the energies of life and will begin to find the snow banks of resignation seductively attractive. If not seriously and resolutely challenged and confronted, such malignant despair can push a person into an accelerating vortex of fragmentation that many have associated with soul loss.

\section{Kierkegaard's Philosophy of Despair}

Soren Kierkegaard, who lived from 1813 to 1855, offers in his Sickness unto Death a description, which I think has never been surpassed, of the way in which despair presents itself. He discusses three things that could be seen as a progressive movement of the experience of this "sickness unto death." In his view, despair is a universal human sickness, yet he believes that it is possible, though very difficult, to cure. He considers in depth three progressive stages.

The first he calls spiritlessness. You and I as Jungians would identify this with people who disappear into the persona in the collective and simply gain narcissistic supplies through social status or career -- or even one's own children. These persons, according to Kierkegaard, are the ones who have the most dangerous form of despair. They may be extremely affluent, or they may be living the "ordinary people" life, but their form of despair is the most dangerous.

The second stage of despair comes closer to a cure of the illness. It's a strange, two-fold movement involving "weakness." The first part Kierkegaard calls despair in weakness. This despair in weakness occurs when people experience what you and I might call "the call to individuation." In this experience they see an epiphany -- a possibility that they might become a person, a person of depth, a person with true individuality. But when their anxiety begins to spike, they retreat in what Jung has called "the regressive restoration of the persona": the attempt to pretend that no connection with an eruption of possibility has occurred.

The second part of the stage two movement is despair about weakness. As you and I know, it is usually impossible to go back to that dreaming innocence of the first stage. The person, beginning now to realize that the door is closed to going 


\section{Moore}

back, starts to despair not only about not being able to go back but particularly about not having the courage to go forward. Kierkegaard talks about how these persons come to hate themselves and hate the fact that they cannot go forward. Indeed, they hate the person that they have become, but they are not connected to the energy they would need to break out of their malaise.

Kierkegaard says that some individuals who have experienced the despair about their weakness do find the inner resources to move beyond it. They then enter the third and final stage of despair - the despair of defiance in which they have an inner connection with the archetypal energies. Here, if the individuals have some talent, they will often experience a rush into radiance, and they may manifest in their lives enormous creativity and achievement as they seek to actually become a real person -- a real self.

But even these people inevitably, according to Kierkegaard, begin to cycle between the ecstasy of achievement and a chronic depression. One is reminded of Mick Jagger's "I can't get no satisfaction." A powerful example of this phase is the great actor -- Sir Lawrence Olivier. His son, speaking of the majestic achievement of his father's career, has noted that his father was never able to achieve the sense of having arrived at what he might have been.

\section{The Cure for Despair: Connecting with a Center Beyond the Ego}

Kierkegaard believed that despair could be cured. He presented his perception of the cure, calling it christian existence. He was, after all, a Christian theologian. In those days there had been no comparative studies of religion as were to follow later in that century. What Kierkegaard called "Christian existence" involved the ego's -- the subject's -- realization that it cannot ground itself -- that it has to find its authentic being in relationship. For Kierkegaard, this was a relationship with a Great Other beyond the subject -- beyond the ego. This was for him, of course, the Christian God.

The perception of a Center beyond the Ego was not limited to Christians. Not long after Kierkegaard's death, European scholars began to study the religious experience, ritual practices, and mythic symbolisms of transformation in peoples all around the world. They discovered in world mythologies a widespread awareness of the importance of a transpersonal center for human existence. The work of the great scholar and friend of Jung's, Mircea Eliade, as he surveyed the history and phenomenology of religion, reveals an almost universal human tendency to look for a Center beyond the subject -- a Center beyond the ego, a relationship with a primal other who is not simply "I." ${ }^{2}$

Eliade's genius was to actually catalog the ways in which there was a quest for the "Center Out There." He found peoples all over the world and from all the tribes 
seeking orientation, meaning and access to power through connection with the axis mundi. The witness of the history and phenomenology of Christian pilgrimage and pilgrimages in other traditions attest to the power of the archetype of pilgrimage and to this longing for contact with the Center, as a resource in our struggle against chaos and despair. The ancient world had humans who knew with Kierkegaard the terrors of history. They also - without benefit of Christianity and some without a concept of God - still had a sense of the need to relate consciously and respectfully to an Other beyond the ego.

We have tended to assume that human beings have always experienced despair in the same way, but based on these historical studies, I am led to raise the question as to whether or not we should be speaking of a "history of despair." Could it be that at a particular time in history human beings lost their understanding of what is necessary to cure despair?

\section{The Mythic Center: Superstition or Archetypal Agenda?}

Was modernity right in associating ritual and mythic quest for the Center with "superstition"? Or, rather, did doing so really dis-empower human life?" Was there something great and wise in these ancient traditions?

Many have talked about the collapse of the "sacred canopy." An influential book for me has been Keith Thomas' Religion and the Decline of Magic. In it, he tracks the rise of modernity and the accompanying loss of the importance of ritual and its participatory practices for the human psyche. Many have called this the modern "loss of a sense for the human." Margaret and I have seen this first-hand. We have just returned from traveling widely through Eastern Europe. Traveling there, you become very aware of the chaos and turmoil that occur in countries which used to be richly, deeply grounded in the mythic imagination, but which have in modern times experienced ideologies that sought to eliminate their connection with those traditions. The effects of the encounter with the terrors of history -- the terrors of Nazism, the terrors of communism -- without benefit of any sense of a transcendent center are painfully visible.

So, was the ancient preoccupation with the Center Out There merely superstition? Was this pre-modern tribal preoccupation with ritual simply a mark of primitive obsessional symptoms? Isn't despair just a bad case of discouragement that a supportive and encouraging therapist can fix? Isn't it just a residue of bad parenting -- echoes of the "bad breast" or "insufficient mirroring by parental self objects"? Can't an approach which focuses primarily on personal trauma and personal complexes successfully eliminate despair if the therapist is really good? Isn't despair just a lack of imagination and a tendency for a person or patient to be lost in various literalisms? Finally, can't the modern problem of despair and the loss of a sense of a Center out there be solved by better psychopharmacology? 


\section{Moore}

Or is the growing despair that we see manifest in all of our institutions somehow related to other phenomena we increasingly observe? For example, we note the growing intensity of the cultural split - a mutual virulent hatred between sociopathic autonomy in culture and various fanatical attempts among spiritual tribes to restore puritanical heteronomy in the form of the Islamic Caliphate or the Christian equivalent. We observe an increasing epidemic of pathological grandiosity and an accelerating decline in the generativity that is needed to garden this planet on behalf of future generations. We need to ask ourselves: is there a relationship between those phenomena? In short, we should ask, is there a fundamental flaw in the contemporary ego -- especially that being constructed in Western Eurocentric culture?

Your answer to these questions will reflect the theory that you frame them with. No phenomena interpret themselves. Clinical phenomena, cultural events, the meaning of history -- events, and data -- do not interpret themselves. In his book, Modern Man in Search of a Soul, Jung himself addressed this crisis facing modernity. In his theory he was bold to posit another Center in the psyche -- one which is other than the ego and is beyond the ego. Jung's work in subsequent years warned us not to dismiss ancient wisdom in a cavalier way. Jung believed that the wisdom of ancient mythology was crucial to an adequate psychology. We will return to his analytical psychology later, but first I want to address this whole question of why theory matters.

\section{Theory Matters in Psychotherapy and Psychoanalysis}

Why would I emphasize theory? I want to offer this, especially to you who are lay persons with interest in Jung, as well as to you who are candidates in training and who are struggling with issues of theory: why does theory matter?

Why do we need to ask this question? Well, it's clear to me that rising numbers of people in various mental health professions, including Jungian analysis, demonstrate little grasp of why we must continue to strive for adequate integrative theory in psychology, psychiatry and psychoanalysis. Some current practitioners, influenced by the anti-intellectual tendencies of American culture -- and especially by New Age thinking -- equate a serious engagement with theory with a "being in your head" that is inauthentic and distancing. They frequently voice the imperative to be more spiritual -- or more "in our bodies." That's what they usually say to me - "Moore, you need to be more in your body." Or they turn to one or more varieties of neo-tribal Shamanism to get initiated. (Now, you need to know, I'm fascinated with Shamanism and recently published in the Jung and Spirituality Series a book by Mike Smith, Jung and Shamanism in Dialogue: Retrieving the Soul/Retrieving the Sacred. I'm simply pointing to some people's use of Shamanism as an escape 
from theory.) Others who have been (invoking my poetic license) sniffing the intoxicating vapors of "glue-less postmodernism" imagine themselves to be beyond the need for developmental theory and diagnostics -- beyond the need for careful study of evolutionary neuro-psychological structures, beyond the vicissitudes of affect regulation.

Still others, on another end of the spectrum, equate using your head with reducing human personality to a bio-chemical machine that can be optimized by pharmacological fine-tuning -- regardless of whatever developments in culture may be occurring and without any attention to the actual impact of social conditions, social class, race, and other cultural variables upon the psyche. In fact, most of this latter group lacks any serious familiarity with cultural studies of the humanities at all -- much less any sophisticated awareness of the significance of the mythological imagination or of the creative aspects of spiritual traditions and ritual practice in the human past.

All of these partisan groups respond to the challenge of creative integrative clinical psychotherapeutic theory by over-simplifying our human situation and thereby do not help us to face either the unique dangers or the unique opportunities of being a psychotherapist or psychoanalyst in our time. I want to share some favorite quotes of mine that illustrate this dilemma. First, "Reality is unforgivingly complex." The human psyche is no exception to that rule - it, too, is unforgivingly complex. The second quote is from H. L. Mencken. ${ }^{3}$ It is one that not just candidates in training but all of us need to remember: "There's always an easy solution to every human problem: neat, plausible -- and wrong!" I love that!

\section{Despair in Analysis, the Analyst, and in Training}

Despair has many traps that afflict those who would be psychological healers in our time. It afflicts analysts and psychotherapists just as it afflicts victims of war or hurricanes. I will be offering a seminar at the Jung Institute on the many ways that despair affects not only our patients but also ourselves - as therapists and clinical supervisors. Here, however, I want simply to note the way despair manifests in relationship to the question of theoretical reflection in our field: in the practice of analysis, in the teaching of theory in our institutes and training communities, and in our research. The magnitude of the theoretical challenge posed by our training or practice -- our chosen work -- can quickly lead to what some of my friends call "analysis paralysis." Overwhelmed and immobilized by complexity, the trainee or analyst takes refuge in one or more of Kierkegaard's stages on the path of despair.

- One analyst or trainee, retreating into a spiritless boredom with theoretical things -- including a depreciation of the importance of theory -- cannot wait to 


\section{Moore}

focus on the "practical nitty gritty" of therapeutic practice. This overlooks what the great field theorist Kurt Lewin once said, "Nothing is more practical than a good theory."

- Another analyst or trainee despairs in weakness and tries to fit in with the latest fad in the peer group.

- And, yet another analyst or trainee despairs about being weak in theory and fears being found out and embarrassed by that lack.

- Finally, there is the analyst or trainee who engages powerfully and creatively in the despair of defiance. For example, a training analyst discovers a new theoretical resource that promises, to this analyst, new certainty and new effectiveness. It seems a lot more respectable than classical Jungian practice. I will never forget the time when I, as a trainee, was part of a class, and one of our analyst instructors had just discovered Melanie Klein ${ }^{4}$ and Object Relations theory. The Jungian training program, under that person's leadership, was so Kleinian that I felt as if we were in London! $!^{5}$ New theory tends to glow with an archetypal numinosity that is reflected in the countenance, the bearing, and the relational field of the analyst. Candidates in training are then expected to show reverence for the analyst's self object. Indeed, the path of despair is all too familiar to trainees and analysts.

\section{Fundamentals of Transformative Process}

We'll come back to our despair about theory in a moment. Another of my purposes here is to speak to our research and training community about the challenge of awakening to the multi-dimensional complexity of all transformative processes. As analytical psychology matures as a theory and practice, it is my hope that we will improve in the challenging task of coming to full consciousness with regard to the complexity of any transformative process in human experience and in the practice of Jungian analysis in particular. For those who have not been involved in Jungian training, you need to know that it's extremely hard to become a Jungian analyst. Not the least of the reasons is that our discipline has tried to follow Jung's example and has attempted to resist simplistic solutions that do not recognize the complexity of the psyche -- both our psyche and those in our patients. What our psychotherapy training programs need -- what any psychotherapy training program needs, I believe -- is a far more adequate approach to the teaching of comparative theoretical paradigms as they impact clinical practice. I've been amazed when teaching licensed psychotherapists at how little facility they have with any theoretical point of view. This fact attests to a disturbing lack of seriousness on the part of clinical educators about the clinical importance of theoretical sophistication. 
Here we should turn to the discipline of philosophical anthropology to assist us in examining any proposed system of transformation in a way that can help us to be critically appreciative of its assertions and the strengths -- as well as the limitations -- of what it offers us. Any system of transformation -- whether spiritual, political or psychological -- always addresses implicitly or explicitly three key elements that exist in any theory of change.

The first question is "What is possible for the human?" What is the theory's explicit or implicit vision -- its normative vision -- of human possibility? That includes assumptions and assertions with regard to the constitutive structures and dynamics of human being. This is called in philosophical anthropology, a "vision of human nature."

The second question is "What can and does go wrong with persons or systems?" We call this "diagnostics" -- the nature and dynamics of human personal and social dysfunction. Every theory has a stance on this.

Third, "What is needed to move toward actualizing the human possibility?" What kind of practice, actions, techniques, interventions, education, illuminations, intuitions, insight, gnosis, and so on are the strategies and tactics of choice? This includes the question of how you really know, as a change agent, what interventions will help and which will simply create more chaos and iatrogenic -or physician-caused - complications.

Crucial for us to remember in any area -- but most certainly in psychoanalytic theory - is that there is no such thing as a perfect theory. Every theory has a shadow. And so, when we examine any theory of psychoanalysis, we will find that every perspective will privilege certain things and depreciate, overlook, or underemphasize others. When we are studying theory then, as psychoanalysts, psychoanalysts in training, or psychoanalytic researchers, we need to ask, "What is the shadow of this theory I'm being offered? What are the issues, concerns, values, agendas, and considerations about the human experience which remain in the background and are either not addressed at all or are under-emphasized?" We have to remember that all theories are points of view -- perspectives which will be cognitive distortions of a complex multi-dimensional reality. Our task in helping analysts-in-training to study theories is to sharpen their awareness of the distortions that exist in all theory. As they strive to form an integrative approach to psychotherapy and analysis which will be as adequate as possible for them, we need to help them become more critical consumers of theory - ever honing their capacity for critical appreciation.

\section{Questions to Ask of Every Theory}




\section{Moore}

Let me propose a few major questions to ask about a theory. The first four questions look at the Theory and the Theoretician. The next group examines the Theory itself.

1. What is the Me-search in the research? Without our caricaturing or engaging in ad hominem attacks on the theorist or theory, what can the biography of this individual offer us in achieving an adequate internal reading of the views of the theorist so that we can understand why and how this theory is structured in the way it is.

2. What is the historical and cultural context of the theory and theoretician? How do the social location, race, class, gender, religion, ethnic background, and so on, influence the horizon created by this theory? It's fascinating to study the way these factors influenced the development of Freudian theory, Adlerian theory, Jungian theory, and others.

3. What major figures, theories, traditions have influenced the theorist and in what way?

4. How does the theory understand personal, social and cultural metabolism? --what I call "the plumbing." What are the operative hermeneutics of culture and personality underlying the assumptions of this theory?

5. Looking at the Theory itself: What is its implicit or explicit ontology? What is its understanding of what is truly Real? What is the nature of reality and being that is implicit in this theory?

6. Is there a root metaphor or root paradigm underlying its vision of transformative process? For instance, with Mircea Eliade and Carl Jung, I've suggested that "alchemy" is actually the fundamental root metaphor for all of their work. In another example, contemporary psychiatry has for decades been dominated by an uncritical appropriation of the "machine model" of the world.

7. What does the theory privilege or inordinately emphasize?

a. Transcendent or Immanent. Does it privilege a transcendent dimension emphasizing what we call the transcendent function -- the collective unconscious? Or does it privilege the significance of things that are immanent in the ego and immanent in the processes of the person -- the biochemical processes?

b. Does it privilege the Vertical or the Horizontal dimension?" For example, you might say, a depth psychologist privileges a vertical dimension of depth and tends to ignore the "horizontal" social systemic aspects of a human personality.

c. Does the theory tend to privilege Technical Reason or Ontological Reason? For example, is it grounded on a digital model of the world? This model, which reduces everything to quantitative analysis, is 
increasingly the dominant image of the human in our world. Ontological reason, in contrast, has a sense for that which is beyond the mastery of current science. This is the realm of mystery, spirituality, and faith.

d. Does the theory privilege the Sacramental or the Prophetic? That is, does it have a sense of what James Hillman has called the "soul in the world," or does it press an explicit moral agenda? Freud, for example, was often called an outstanding moralist.

e. Does the theory privilege the Self / Individual or does it focus more on World / Culture / Society?

f. Does the theory favor Dynamics or Form? In other words, does it depreciate diagnostic categories -- seeing them as interfering with the healing process? Theories that deemphasize diagnosis are privileging the dynamic. Or does the theory privilege form, i.e. asking "how does the psyche become structuralized and integrated, and what implications does this have for diagnosis?"

g. Individuation or Participation -- What is the relationship between the individual and the collective? For example, theories differ on the importance of relationality and the intersubjective field for the maturation of personality.

h. Freedom or Destiny -- does the theory have some place in it for the human subject unexplainable by any objective theory? Or does it reduce human beings to genetic and biochemical destiny?

i. Does the theory privilege Gnosis -- that is, saving knowledge? Or does it emphasize Praxis / Practice as in psychotherapeutic technique? Is there any attention to behavior and behavioral interventions? Is there any attention to actual enactments to help people confront their issues?

8. What sources of data are drawn upon as a foundation for grounding an adequate theory of change? Does it draw on any natural sciences -- other psychoanalytic traditions? Does it draw on empirical psychological research, comparative mythology, philosophy, comparative spiritual traditions, humanistic or cultural studies?

Theories vary widely in their approaches to these issues. Reflecting on these questions can help us address the complexity of the multi-dimensional human reality.

\section{Theoretical Reflection as Play}

The complexity of studying comparative theory in depth requires us to get into an attitude of play. A playful modality can get us back in touch with our nature as homo ludens. We do our best creative work in play. Similarly, any Jungian analyst 


\section{Moore}

or trainee should be able to enter into and play with this kind of reflection on theories. This should be cultivated as an important aspect of our community of learning in order to raise the level of our communal discourse on psychotherapy and analysis.

When and if we do this, we'll be better at a critical appreciation -- not just arrogant dismissal -- of the inter-disciplinary resources which feed our attempt to develop theory and practice. We will become more aware of the awesome, one might even say "grandiose," challenge of the path we have chosen as analysts and would-be transformers. Don't misunderstand me: I've always recommended that people befriend their grandiosity, and a number of my colleagues have certainly done that. Consciously befriending our grandiosity and playfully scrutinizing theory will help us to be a little more humble with regard to the perspectives we've chosen to advocate.

And finally, a playful approach will make us more aware of our need for each other and for creative collaboration as we seek to move analytical psychology forward as a discipline.

\section{Theory Matters in Practice}

In other settings I have had more time to discuss theory matters as they impact psychotherapeutic practice. ${ }^{6}$ Here I will simply refer to Bill Clinton as an illustration. When it comes to theory matters in practice, Bill Clinton would remind us, "Some dogs don't hunt." In this case, it applies to the impressive, intelligent folk who proudly offer us shiny new theories or anti-theories which, however erudite, fail to aid us when we're in the trenches with souls in despair and societies in chaos. As practitioners thinking about theory and practice, we mustn't forget to ask that all important technical psychoanalytic question, "Where's the beef?" -- "Where's the beef in this for my actual practice?"

The care with which we approach such reflection also influences the practice of our life together in psychoanalytic institutes. Too well we know that conflicts in theoretical perspectives can lead to the splitting of institutes. Some analysts and candidates in the despair of spirit-less-ness take refuge in boredom with theory and avoid making an effort to bring anything to the party of creative theoretical play in our training community.

Others, analysts in an extreme of the despair of defiance, take refuge in an inflated certainty and quickly, gladly draw the dis-empowering idealizations of those analysts and trainees who are caught in the despair in weakness. You can recognize this dynamic since analysts operating out of an inflated despair of defiance enjoy depreciating other theories and the people who use them. They usually seek to generate shame responses in those who don't agree with them. 
Alfred Adler called this "the depreciation tendency" -- one of the chief marks of unconscious grandiosity. You can detect its presence by what I call "the stench of certainty." This stench of certainty issues from the inability to be critically appreciative of those who offer alternative perspectives. This rapidly leads, in institutes, to institutional despair and the devolution from theory to ideology.

Any serious psychoanalytic theory is heuristic -- related to data in a way that can be challenged or changed in the face of new data. Ideologies, in contrast, are lost in their own utopian certainties, and they engage in ad hominem arguments and depreciation of those who don't sign up for uncritical membership in their tribe. This, of course, leads to the end of dialog and the despairing retreat into conformity and consensus, and, as we've seen, even the splitting of psychoanalytic institutes. This happens, not just among Jungians, but in all traditions -- under the guise of theoretical conflicts among analysts.

We must try to get beyond all these forms of despair about developing analytical psychology as a clinical theory and as a resource for those who wish to understand the interaction between cultures and the psyche as it impacts the human future.

\section{Stewarding Jung's Legacy}

I return to Jung's own theory and to the challenge that faces us in trying to steward his legacy. There are four ways that I think that Jung's theory needs to be stewarded and continually developed:

First, Jung's theory offers a paradigm for psychoanalytic science and a vessel for integration in the human sciences among the physical sciences, the cultural sciences, and the science of the soul.

Second, Jung's legacy holds insights for those who seek a deeper understanding of psychopathology and its causes as well as the challenge of effective treatments that take into account the reality and power of archetypal energies.

Third, Jung offers a legacy of leadership for those concerned with responsible spiritual practice and leadership in an age of religious conflict.

Fourth, Jung offers a foundation for those concerned about wise political leadership in an age of anxiety and an epidemic of archetypal contagions.

I don't need to review the different theoretical camps in the Jungian community now. We all know that there is a need to get beyond any treatment of Jungian psychology as dogma. We also know that in carrying Jungian theory forward we must -- without uncritical idealization -- learn from our Freudian colleagues and post-Freudian colleagues in their attention to micro-systemic processes. We need to learn from them without losing a sense of the Copernican paradigm shift that we believe occurred in Jung. 


\section{Moore}

Many of us feel that we also need to get beyond the anti-scientific nihilism of true believer deconstructionists and not continue the uncritical idealization of intellectual pyrotechnics that occurs in contemporary postmodern discourse. We need to admire and learn from the postmodernists' careful attention to the primacy of personal narrative, their radical suspicion of the constructions of the ego, and their attention to the hidden power agendas of gender, race and class without buying into the grandiose attempt of some to de-legitimize scientific inquiry.

\section{The Way Forward}

In the remainder of this presentation I would like to outline some elements of what I call a Neo-Jungian approach to theory and research in analytical psychology -- not classical Jungian, not post Jungian, but Neo-Jungian. It is Neo-Jungian in the sense that it attempts to stay true to Jung's primal discoveries about the importance of the ego's relationship to a transpersonal, trans-egoic Other. We need to formulate an approach to psychotherapeutic interventions that takes the great forces of the collective unconscious into adequate consideration. This includes more effective attention to the role of the flooding of archetypal energies in psychopathology as well as more emphasis on the challenge of containing, regulating, and channeling these energies. We must broaden and deepen the sources of data we use in Jungian research. Because of the multi-dimensional and integrative scope of any serious attempt to carry Jungian psychoanalysis forward, interdisciplinary cooperation is not just desirable - it is necessary and urgent, given the radical need for greater self-awareness on the part of our species.

Following Jung, we need to continue serious research into the deep structures of the human psyche:

- What are the deep structures of the human psyche?

- How are they organized?

- What relationship exists between these deep structures and the on-going processes of human evolution?

- What relationship exists between these deep structures and human epigenesis? In what way do they relate to the normal developmental process in human personality as the individual moves through the life cycle?

- What role do these deep structures play in our attempt to account for differences in the formation of human personalities?

- What are the implications of these deep structures for our understanding of the shape of psychopathology? Certainly we appreciate tools drawn from other traditions that focus on the drama of the family in the origin, role, and impact of personal trauma in psychopathology. But we must stop ignoring or paying so 
little attention to the role the Objective Psyche plays not only in the seductiveness of pathological states but also in determining the particular forms which psychopathology takes in a particular personality. In what way could such new knowledge impact our approach to adequate treatment planning?

- What does the human cultural, social and interpersonal environment need to provide as evocation of nutriments for the optimal deployment of the information stored in these deep structures?

- What is the relationship between these deep structures and the human experience of subjectivity? Jung was radically interested in this question, and we must continue this line of inquiry in our research today. Can we do any better at mapping the phenomenology of human experiences of subjectivity without cavalierly disconnecting this mapping from the burgeoning scientific evidence about the biological, neuropsychological and neurosocial dynamics that provide a substrate of embodiment for human subjectivity?

- What is the relationship between these deep structures and the recurrent patterns which emerge in the human mythic imagination, ritual practice, contemporary cultural creations, and spiritual experience?

- What would a mature human being be able to do if the deployment and integration of these coded potentials of the collective unconscious were good enough?

- What would happen if the deployment and integration of these coded potentials in the Objective Psyche were optimal -- that is, taken to the zone of creativity and flow? This is what you and I as Jungians might call the realm of the further reaches of the individuation process. And this is the place that the individuation process interfaces with integrative human spirituality.

\section{Analytical Psychology and the Quest for Consilience in Human Knowledge}

The sociobiologist (I'll make my postmodernist friends nervous here) E. O. Wilson has called for a new attempt to bridge the physical sciences and the humanities in moving toward a sense of consilience in human knowledge -- that is, an integration between the two cultures of the humanities and the sciences. Wilson undoubtedly did not have us in mind when he set this goal for contemporary science, but we should remember that the great anthropologist Victor Turner noted the promise of Jung's psychology in facilitating just such a bridging of inquiry between the two cultures. He envisioned the role of Jungian psychology in offering an integrated model for research into brain, culture, and personality in a coherent scientific inquiry.

In my personal view, Jungian psychologists may well be the first theorists and analytical psychology the first discipline where such a real consilience begins to 


\section{Moore}

appear. What we are dealing with here is the vision of a scientifically grounded view of psychoanalysis which is not so arrogant that it loses the existential human subject or the mythic imagination.

Of course, looking at all of these challenges is enough to make any individual despair. This is why we need to come to see ourselves as a psychoanalytic learning community. Everyone -- every analyst, every trainee, every researcher -- has something to bring to the party of theory and theorization in order to contribute to this great tradition.

In closing, I want to name the way in which despair affects us when we try to face these challenges. As one of my friends used to say, "Despair always represents itself as a possibility -- in every moment." We have to realize that facing this challenge which presents itself to us as analytical psychologists requires immense courage. Where are we going to get that courage so that we don't retreat into one or another form of the cul de sac of despair as we seek to do theory? My sense is that everybody here has some awareness of being connected to the unconscious with its incredible archetypal energies. And it is only there that we are going to find the fuel it takes - or "the juice" - as I tell my graduate students. The unconscious is the only place we're going to get the juice we need to fuel our courage for working together on this.

We'll be able to tell how well we're doing in playing with theory in our learning community as analysts, trainees and researchers when we have more fun with it. When we lighten up -- stop being so serious and certain, as if we really knew what we were talking about -- only then will it become fun: a kind of a liminoid, joyful, almost ecstatic practice of celebrating this tradition. That is possible, and it is my hope that we will begin to see this joy manifest in Jungian training and in the Jungian analytical community as we go forward.

\section{Works Cited}

Eliade, Mircea. The Sacred and the Profane. Harcourt, 1968.

Jung, Carl. Modern Man in Search of a Soul. Harcourt, 1955.

Kierkegard, Soren. The Sickness Unto Death: A Christian Psychological Exposition for Edification and Awakening. New York: Penguin Press, 1989.

Smith, C. Michael. Jung and Shamanism in Dialogue: Retrieving the Soul/ Retrieving the Sacred. Paulist Press, 1997. 
Thomas, Keith. Religion and the Decline of Magic: Studies in Popular Beliefs in Sixteenth and Seventeenth Century England. Simon \& Schuster, 1986.

Turner, Victor. "Body, Brain, and Culture." Zygon: Journal of Religion and Science 18 (1983): 22146.

Wilson, E.O. The Unity of Knowledge. Random House Inc., 1998.

\section{Notes}

${ }^{1}$ This address was given by Dr. Robert L. Moore at the National Conference of Jungian Analysts and Candidates in Chicago, IL September 23, 2005.

${ }^{2}$ See also Robert L. Moore, The Archetype of Initiation: Sacred Space, Ritual Process, and Personal Transformation (Xlibris, 2001), pp. 23-35, 90-93, 138-142, 157-158.

${ }^{3}$ I thank my friend Ray Zemon for introducing me to this quotation.

${ }^{4}$ Melanie Klein (1882-1960) was a post-Freudian analyst and theorist, best known for her object relations theory.

${ }^{5}$ Klein's work was well received in London, United Kingdom, which is now the home of the Melanie Klein Trust.

${ }^{6}$ Robert L. Moore, "Structural Psychoanalysis and Integrative Psychotherapy: A NeoJungian Paradigm," Lecture 720 CD; "Archetype, Compulsion, and Complex: A NeoJungian Approach to Structural Diagnosis in the Practice of Psychotherapy," Lecture 721

CD (CG Jung Institute and Institute for Psychoanalysis, Culture and Spirituality, 2006) www.jungchicago.org. 